\title{
BIOÉTICA, TRASPLANTE DE ÓRGANOS Y DERECHO PENAL EN COLOMBIA*
}

\author{
Yolanda M. Guerra García** \\ Álvaro Márquez Cárdenas***
}

Fecha de recibido: 15 de junio de 2011

Fecha de aprobación: 16 de noviembre de 2011

Artículo resultado de Investigación

\begin{abstract}
Resumen
Este artículo presenta los lineamientos del Derecho Penal que trascienden los conceptos de trasplantes de órganos y las implicaciones Bioéticas de los mismos. Del mismo modo se establecen algunos de los principales criterios relacionados con el debate bioético en torno al problema de la Donación y Trasplante de Órganos, problemas relacionados con temas como la Muerte Encefálica, el consentimiento informado, Justicia y Distribución, los Xenotrasplantes y la Clonación Embrionaria entre otros.
\end{abstract}

\section{Palabras clave}

Derecho penal, Bioética, Donación, trasplante de Órganos, Consentimiento Informado

\section{BIOETHICS, ORGAN TRANSPLANTATION AND CRIMINAL LAW IN COLOMBIA}

\begin{abstract}
This Article presents the main subject of criminal law which transcends the theory of organ transplantation and the bioethical implications of same. In the same way establishes some of the principal criteria related with the bioethical debate around the problem of donation and organ transplantation, in subjects such as encephalic death informed consent, justice and distribution, Xeno transplantation, embrionary cloning, among others. Subsequently, the situation of the practices of organ transplantation in the field of Latin America, analyzing
\end{abstract}

* Este artículo hace parte de la investigación "Bioética, trasplante de órganos y legislación comparada" aprobada por la Universidad Militar Nueva Granada con el código Hum 780, Grupo titular de la investigación Liderazgo (categoría A1 en Colciencias), Directora Yolanda M. Guerra.

** Abogado, Magister, Doctor y PostDoctor, Directora del grupo Liderazgo, categoría A1 en Colciencias, docente de la Facultad de Educación y Humanidades de la Universidad Militar Nueva Granada. Correo electrónico: yolanda.guerra@unimilitar.edu.co

**** Abogado, Doctor en Derecho por la Universidad Complutense de Madrid, Especialista en Derecho Penal, Magister en Estudios Políticos Universidad Javeriana, Estudios de otro Doctorado en Derechos Fundamentales Universidad Carlos III de Madrid. Miembro principal sala de CONACES Ministerio de Educación. Miembro activo del grupo Liderazgo y de Derecho Público. Docente de la Facultad de Derecho de la Universidad Militar Nueva Granada. Correo electrónico: alvaro. marquez@unimilitar.edu.co 
the state of these activities according to the registries of Latin American and Caribbean Transplant Society (STALYC).

\title{
Keywords
}

Criminal Law, Bioethics; Organs Donation and Transplantation; informed Consent.

\section{BIOÉTICA TRANSPLANTE DE ÓRGÃOS, E DIREITO PENAL NA COLÔMBIA}

\begin{abstract}
Resumo
Este artigo apresenta as diretrizes do Direito Penal que transcendem os conceitos de transplantes de órgãos e implicações bioéticas do mesmo. Da mesma forma estabelece alguns dos principais critérios relacionados ao debate bioético sobre a questão da Doação e Transplante de Órgãos, problemas relacionados a temas como morte cerebral, o consentimento informado, da Justiça e Distribuição, xenotransplante e clonagem de embriões e outros.
\end{abstract}

\section{Palavras-chave}

Direito Penal, Bioética, doação, transplante de órgãos, o consentimento informado

\section{INTRODUCCIÓN}

Este artículo hace parte de una investigación en la cual se ha escogido como problema de investigación determinar cuáles son las normas que rigen el asunto del trasplante de órganos en Derecho comparado, y en el artículo presente, concretamente la normatividad vigente en lo atinente a la legislación penal y el tema de los trasplantes de órganos.

Como objetivo general, se tiene entonces adelantar una investigación que permita analizar críticamente la normatividad vigente en materia penal de los trasplantes de órganos en Colombia.

Los procesos de trasplante de órganos son prácticas, cuya construcción histórica ha permitido que actualmente se encuentren enmarcados en los principios o máximas éticas del respeto al individuo, la no maleficencia, la beneficencia y la justicia.

Así mismo, el continuo desarrollo tecnológico y científico ha planteado para el asunto de los trasplantes, nuevos desafíos cuya característica principal es un amplio espectro de riesgos e incertidumbres. La amplia demanda de órganos contrastada con la mínima oferta, especialmente en los países tercermundistas en donde existen obstáculos de diversa índole como los religiosos, políticos, culturales, epistemológicos, etc.

Por esta razón, se hace imperante la necesidad de construir nuevas epistemologías y concepciones basadas en el respeto de la integridad del individuo, que permitan a partir de la Bioética, la adecuada toma de decisiones por parte de los profesionales de la salud, el continuo debate y reflexión sobre la forma de mejorar todas las practicas asociadas y las proyección de los beneficios y riesgos implícitos.

\section{TRASPLANTE DE ÓRGANOS}

Dentro de los muchos aspectos que puedan converger en el debate bioético al abordar el problema de los trasplantes de órganos, los Doctores Juan Carral Novo y Jaime Parellada Blanco (2003), miembros del grupo de trasplantes del Hospital Militar Central: Dr. Luis Díaz Soto de Cuba, destacan tres importantes criterios que deben tenerse en cuenta, particularmente, en el uso de componentes anatómicos provenientes 
de cadáveres, los cuales son: el análisis de la Muerte Encefálica como criterio de Donación, el abordaje del problema del final de la vida (relación Bioética y Muerte) y lo referente a la extracción de órganos.

De estos criterios destacan que en los procesos de Donación de órganos, hay que prestar especial atención a la voluntad del Donante Fallecido, por lo cual, consideran pertinente acudir a uno de los principios básicos de la Bioética: el principio de la Autonomía, que refleja el consentimiento del individuo que ha fallecido con donar o no sus órganos para procesos de trasplante (Carral, J; Parellada, J; 2003).

Igualmente los autores citan una característica común en los países de América Latina en el caso del Consentimiento Afirmativo en los procesos de Trasplantes:

En los países de América Latina, donde se ha establecido la ley del consentimiento afirmativo del donante, los familiares tienen la autoridad para vetar el consentimiento de un familiar de igual parentesco o de un parentesco más lejano con la persona fallecida. En otros, los familiares no pueden dar su consentimiento para que se utilice el cadáver, si conocen alguna objeción del finado respecto a la donación. (Carral, 2003).

De acuerdo con un informe de la Dirección de Desarrollo de Servicios de Salud de la Secretaría de Salud de Bogotá (2007) el Trasplante de Órganos se define como la sustitución de un órgano o tejido enfermo, por otro sano, procedente de un donante vivo o de un donante en muerte encefálica. Igualmente, el trasplante de un órgano o tejido tiene aplicabilidad cuando se presentan dos condiciones a saber: primero que el órgano del paciente receptor haya sufrido una alteración que se considera es de carácter irreversible y segundo, cuando no existe otra alternativa de tratamiento para la reparación del órgano o tejido alterado y que atente contra la vida de la persona.

\section{IMPLICACIONES BIOÉTICAS EN EL TRASPLANTE DE ÓRGANOS}

Dentro de los muchos aspectos que puedan converger en el debate bioético al abordar el problema de los trasplantes de órganos, los Doctores Juan Carral Novo y Jaime Parellada Blanco, miembros del grupo de trasplantes del Hospital Militar Central, destacan tres importantes criterios que deben tenerse en cuenta, particularmente, en el uso de componentes anatómicos provenientes de cadáveres, los cuales son: el análisis de la Muerte Encefálica como criterio de Donación, el abordaje del problema del final de la vida (relación Bioética y Muerte) y lo referente a la extracción de órganos. (Carral, J; Parellada, J; 2003).

De estos criterios destacan que en los procesos de Donación de órganos, hay que prestar especial atención a la voluntad del Donante Fallecido, por lo cual, consideran pertinente acudir a uno de los principios básicos de la Bioética: el principio de la Autonomía, que refleja el consentimiento del individuo que ha fallecido con donar o no sus órganos para procesos de trasplante (Carral, J; Parellada, J; 2003).

Igualmente los autores citan una característica común en los países de América Latina en el caso del Consentimiento Afirmativo, que es cuando la persona donante conscientemente firma un documento o establece en otro medio idóneo que es su voluntad donar sus órganos después de muerte, se opone al consentimiento presunto:

En los países de América Latina, donde se ha establecido la ley del consentimiento afirmativo del donante, los familiares tienen la autoridad para vetar el consentimiento de un familiar de igual parentesco o de un parentesco más lejano con la persona fallecida. En otros, los familiares no pueden dar su consentimiento para que se utilice el cadáver, si conocen alguna objeción del finado respecto a la donación. (Carral, 2003). 
Desde el punto de vista de Méndez y Silveira (2007) el consentimiento Informado se ha convertido en el derecho que ha permitido la autodeterminación del paciente, el respeto por su voluntad, haciendo que este tenga un acercamiento más directo con el médico. En palabras de Garzón (2009) "el consentimiento Informado es la expresión más pura del respeto a la autonomía del sujeto".

El Consentimiento Informado, que según la definición de Yolanda Guerra en la obra Trasplante de órganos, Bioética y legislación comparada (2011) es aquel que se da cuando el paciente, en este caso el donante de órganos, acepta y conoce todos los riesgos e implicaciones en su salud y en todos los demás aspectos de su vida que conllevan el hecho de donar sus órganos, sobre todo si está vivo, como requisito para el desarrollo de las prácticas clínicas e investigativas surge como consecuencia de dos principales sucesos: el desarrollo de la Teoría Legal Estadounidense que declara el C..E. aplicable en el ámbito clínico y las Declaraciones Internacionales resultantes de la delimitación de los procesos de Investigación en Seres Humanos, como el Código de Núremberg, la Declaración de Helsinki entre otros (Garzón, 2009;p.14).

Méndez y Silveira (2007) argumentan que el término Consentimiento Informado surgió en el año de 1957, en donde es mencionado por primera vez en una sentencia judicial en una corte norteamericana, y que dicho término tenía como propósitos iníciales: brindar una información adecuada al paciente antes de cualquier intervención clínica y otorgar al paciente la potestad de rechazar o autorizar cualquier procedimiento.

Carral y Parellada (2003) enfatizan que el cambiante sentido que tiene el concepto de "Muerte", obliga a todas las autoridades involucradas en los procesos de trasplante a estar analizando constantemente las implicaciones tanto éticas como científicas para su formulación, y esto fundamentalmente, en el caso de la formulación más adecuada frente al concepto de "Muerte Encefálica" como criterio de donación, el cual debe ser independiente a este proceso.
De acuerdo a lo anterior es preciso que todos los actores involucrados en la práctica de la obtención, la donación, el manejo y el trasplante de órganos, y particularmente los profesionales encargados de los procedimientos clínicos de trasplantes, adquieran un conocimiento mas preciso de lo que significa el concepto de Muerte Encefálica, a fin de preservar la integridad y los derechos del individuo; en otras palabras, no infrinjan el principio bioético de la No Maleficencia.

De todos modos, los autores del presente artículo resaltan la importancia de brindar una educación adecuada a la población, que le permita conocer las bondades de la donación de órganos y la posibilidad de salvar vidas. Con lo cual los individuos sean concientes de la posibilidad de donar sus órganos, si en algún momento de su vida llegasen a permanecer en el estado de coma, más conocido como muerte encefálica.

En torno a los procesos de extracción de órganos, los autores de este artículo consideran que es necesario tener en cuenta algunos aspectos importantes:

- La optimización de las condiciones físicas del potencial donante, a fin de preservar lo mejor posible los órganos destinados para trasplante

- La claridad en la comunicación con los familiares tanto del donante como del receptor; lo cual implica simplicidad cuando se maneje información por escrito

- El aseguramiento de la calidad en cuanto a personal que participara en el procedimiento

- La adecuación de los espacios y recursos físicos hospitalarias en los que el trasplante tendrá lugar (Carral y Parellada, 2003).

Por su parte, María Casado (2007) también sostiene que la necesidad de recurrir a la elección de Muerte Encefálica como criterio de muerte en los procedimientos médicos, -en este caso los trasplantes de órganos- es un aspecto que implica una responsable toma de decisiones ya 
que la misma afecta por igual a todos los actores involucrados en estos procesos, tanto a nivel clínico como en los ámbitos moral y jurídico.

Así mismo, afirma que dentro de los nuevos debates éticos en el campo de la donación se encuentran una mayor necesidad de órganos para trasplante (alta demanda) y el auge de la donación inter-vivos; $y$ dentro de los nuevos desafíos en torno a los trasplantes se encuentra el desarrollo de dos importantes campos: los xenotrasplantes y la clonación de células embrionarias para la creación de órganos (Casado, 2007).

En torno al caso de los Xenotraplantes ${ }^{1}$ argumenta que a pesar del avanzado desarrollo tecnológico, es importante tener en cuenta tanto el tema del rechazo del órgano implantado del animal en el cuerpo del humano, como en el caso de los corazones del cerdo, un animal que tiene un fenotipo similar al del ser humano. (Casado, 2007).

Además, Casado, hace un llamado a la necesidad de replantear la función del consentimiento del paciente como única garantía que sustente estos procesos, puesto que llevan implícitos unos riesgos que son imprevisibles y difícilmente evaluables, como es el caso de la reacción negativa y de rechazo de un paciente, ante el hecho de que le sea trasplantado un tejido proveniente de una fuente animal (Casado, 2007).

Y frente al uso de células embrionarias ${ }^{2}$ como fuente de creación de algunos órganos para trasplante, Casado propone la necesidad de fundamentar valores morales y sociales sustentados en los

1 La definición médica de xenotrasplante es el trasplante de órganos, tejidos o células de una especie a otra. Es decir, la utilización de órganos de animales para su implantación en el hombre

2 Una célula madre o célula embrionaria es aquella que tiene la capacidad de auto renovarse mediante divisiones mitóticas o bien de continuar la vía de diferenciación para la que está programada y, por lo tanto, producir células de uno o más tejidos maduros, funcionales y plenamente diferenciados en función de su grado de multipotencialidad principios del marco de los Derechos Humanos, que unifiquen las tradicionales posiciones encontradas en el abordaje de esta problemática, como lo son, la posición evolucionista "que considera al embrión como parte de un proceso evolutivo potencial" por tanto susceptible de manipulación y la posición teológico-metafísica, como la nombra ella, que ve al embrión como "un individuo desde el momento de su concepción". (Casado, 2007, pp. 264- 265).

Otra problemática íntimamente ligada a lo expuesto anteriormente es el caso de la Clonación de Embriones Humanos, que de acuerdo con López Trujillo (2006) ha tenido un gran impacto mundial entre las distintas autoridades de los países del mundo, en particular la Institución de la Iglesia Católica y algunos gobiernos conservadores. De ella -la clonación- pueden derivarse dos posibilidades; la reproductiva, que procure el desarrollo completo del sujeto y la científica cuyo objetivo es la investigación específica a partir de un embrión en estado de preimplantación.

Otro importante aporte, desde un enfoque epistemológico del acercamiento entre la bioética y los trasplantes lo realiza Guillon (1996 en Thomas \& Kushner) en su artículo "Trasplantation and Ethics", desde la construcción de dos posiciones encontradas; es decir, en el sentido que algunas personas consideran el "hecho de usar partes de cuerpos de otras personas" como una idea sumamente repulsiva, casi que inmoral; contrario a lo que piensan otras, que con el simple hecho de calificar dichas prácticas como "inmorales, pasan al plano de lo ambiguo, lo cual implica que deben tenerse claros conceptos para la comprensión de estos procedimientos como alternativas a un posible caso de trasplante.

Más adelante, Guillon propone que para el abordaje de los procesos biomédicos desde un entorno ético, es preciso tener en cuenta las cuatro máximas establecidas por la Americans Beauchamps and Children, que en teoría corresponden a los cuatro principios básicos de la Bioética Moderna: el respeto por la autonomía 
y la autodeterminación de las personas, la no maleficencia que involucra en no perjudicar o herir al individuo, la beneficencia y la justicia.

Y precisamente es en este último principio en que el autor hace énfasis, por lo que afirma que, en el contexto de los trasplantes, pueden surgir varios tipos de Justicia como todos los demás procedimientos médicos y quirúrgicos, por lo cual se pregunta, en términos de Justicia y Equidad ¿Cuántos de los recursos disponibles deben ser dispuestos para este tipo de tratamientos (Incluyendo problemas de investigación y desarrollo) en comparación con otros tratamientos? (Guillon, 1996).

Es aquí donde plantea el fenómeno del "Comercio de Órganos" como salida a la escases de recursos, por lo cual establece que aunque la mayoría de países del mundo tienen prohibido la comercialización de los órganos de las personas, hay algunas tendencias incipicientes aún no formalizadas, que verían en la compra y venta de órganos una salida moralmente aceptable desde la perspectiva de los donantes/vendedores, siempre y cuando se cuente con un sistema controlado de comercio de órganos, puesto que este favorecería y promulgaría aspectos como el respeto por la autonomía del donante y la transacción en términos de justicia distributiva (Guillon, 1996).

De otra parte, y como se mencionó anteriormente, gran parte de los procesos de trasplante de órganos está asociada a la toma de decisiones oportuna y rápida de los profesionales de la salud y de las entidades autorizadas para su práctica, por lo que en este sentido, la participación activa de los comités de Bioética de dichas entidades cobra una mayor importancia.

Por esta razón, podemos acudir a lo que sostiene Antonio Pardo (2010) en el sentido que por su misión orientadora, los comités de bioética se encargan de brindar conocimientos a los profesionales que tienen a su cargo la realización de los procesos clínicos, sin desconocer que en ocasiones se presentan conflictos relacionados con la incompatibilidad en los juicios planteados por ambos actores.
Es en este punto, en que el autor plantea que los comités de bioética son de gran utilidad por dos razones: la primera establece que con sus juicios permiten clarificar situaciones nuevas o que generen algún inconveniente a los profesionales de la salud y en segundo lugar que no pretenden reemplazar la propia decisión del profesional de la salud, sino solamente ilustrarla. Lo cual significa que toda decisión moral del profesional de la salud es personal e intransferible, por lo que una vez emitido el consejo o recomendación por parte del comité de bioética, la responsabilidad la asume el profesional (Pardo, 2010).

Diego Gracia en su "Historia del Trasplante de Órganos", señala algunos de los dilemas bioéticos del trasplante de órganos así: históricamente un proceso evolutivo de estos procedimientos, en los que en un principio eran considerados como prácticas inmorales y susceptibles de penalización, pasando por procesos aceptados solo desde el plano experimental y posteriormente se establecen como fruto de un debate entre lo empírico y lo terapéutico, que concluyó que todo procedimiento de trasplante debía pasar por una validación para ser considerado práctica clínica aceptable. Finalmente concluye que el problema de los trasplantes es abordado desde el análisis de las "condiciones en que debe ser aplicado como técnica terapéutica", tras superar el problema de la beneficencia o maleficencia en su aplicación en seres humanos (Garzón, 2000).

\section{IMPLICACIONES PENALES DEL TRASPLANTE DE ÓRGANOS}

$\mathrm{El}$ aspecto del trasplante de órganos tiene en Colombia, implicaciones de carácter penal que es necesario conocer para evitar caer en ellas. La Ley 919 de 2004, adiciona al código penal varios tipos penales con el fin de prohibir la comercialización de componentes anatómicos humanos para trasplante. En esta Ley se estableció en el artículo $1^{\circ}$ y $2^{\circ}$ los nuevos delitos sobre el tráfico de órganos y el artículo $3^{\circ}$ sanciones administrativas a las entidades y clínicas que fungen como banco de órganos. Textualmente dicen estas disposiciones: 
Artículo $1^{\circ}$. La donación de componentes anatómicos; órganos, tejidos y fluidos corporales deberá hacerse siempre por razones humanitarias. Se prohíbe cualquier forma de compensación, pago en dinero o en especie por los componentes anatómicos.

Quien done o suministre un órgano, tejido o fluido corporal deberá hacerlo a título gratuito, sin recibir ningún tipo de remuneración por el componente anatómico. $\mathrm{Ni}$ el beneficiario del componente, ni sus familiares, ni cualquier otra persona podrá pagar precio alguno por el mismo, o recibir algún tipo de compensación.

Parágrafo. Las instituciones que funcionen con la debida autorización como bancos de tejido y de médula ósea y las instituciones prestadoras de servicios de salud con programas de trasplantes habilitados, podrán cobrar los costos ocasionados por la hospitalización del donante vivo, el cuidado médico del mismo, el diagnóstico, la extracción, la preservación, las pruebas o exámenes requeridos previamente para la donación o el suministro, el transporte, el valor de las pruebas inmunológicas y de histocompatibilidad indispensables para la realización del trasplante, el valor del trasplante, gastos de hospitalización, cirugía y cuidado médico postoperatorio del paciente trasplantado y del donante, el suministro de medicamentos y los controles subsiguientes a dicho procedimiento.

Artículo $2^{\circ}$. Quien trafique, compre, venda o comercialice componentes anatómicos humanos, incurrirá en pena de tres (3) a seis (6) años de prisión.

Parágrafo. En la misma pena incurrirá quien sustraiga un componente anatómico de un cadáver o de una persona sin la correspondiente autorización, quien participe en calidad de intermediario en la compra, venta o comercialización del componente o quien realice publicidad sobre la necesidad de un órgano o tejido sobre su disponibilidad, ofreciendo o buscando algún tipo de gratificación o remuneración.
Artículo $3^{\circ}$. Las instituciones autorizadas como Bancos de Componentes Anatómicos y Centros de Trasplantes que participen de un proceso de extracción o trasplante contraviniendo la presente ley, o las normas previstas para la presunción de donación de que trata el artículo $2^{\circ}$ de la Ley 73 de 1988 , serán sancionadas con multa de veinte (20) a cien (100) salarios mínimos legales vigentes.

El trasplante de un órgano implica la necesidad de tener quien lo done. Muchas veces por falta de información, por la falta de cultura, o por motivos relacionados con la religión, se torna complejo encontrar personas que estén dispuesta a donar un órgano.

El trasplante de órganos siempre implica al donante, lesiones personales con incapacidad para laborar, con deformidad permanente, con disfunción del órgano par, o con una enfermedad grave, y en no poco casos se puede plantear una posible tentativa de homicidio si el órgano se ha obtenido sin el permiso del donante.

El trasplante de un órgano o tejido puede resultar fundamental para salvar una vida o mejorar la condición del enfermo que por deficiencia funcional de un órgano necesita un cambio. El trasplante resulta una expectativa de mejor calidad de vida para quien padece una dolencia generada por una enfermedad que se puede solventar con un trasplante de órgano.

Antes de la Ley 919 de 2004, el Código Penal solo castigaba los trasplantes ilícitos o irregulares considerándolos como un delito de lesiones personales, pero el legislador considero que era necesaria la tipificación penal de la comercialización de componentes anatómicos humanos para trasplante, la promoción mediante la publicidad y del denominado turismo de trasplantes.

En opinión de algunos doctrinantes estiman que el trasplante de órganos debe despenalizarse, permitir que algunas personas en este estado de crisis económica, tenga la oportunidad de obtener uno ingresos con la venta de uno de 
sus órganos par sin arriesgar sus vidas. Es decir, permitir abiertamente que los ciudadanos puedan, mediante una contraventa legal, disponer de un pulmón, un riñón o parte de los intestinos etc. Esto es, que se pueda vender un órgano propio de los que son pares, simétricos. Esta posición se critica porque fomentaría el mercado negro de órganos, se impulsaría el homicidio y las lesiones personales. Muchas personas llegarían a matar o secuestrar para cobrar por los órganos de las víctimas, algo parecido a "los falsos positivos" en nuestro país.

Ante la gran demanda de órganos, e imposibilidad de acabar con el tráfico o comercialización, algunos expertos explican que la mejor forma de garantizar la salud y seguridad de los donantes y receptores consiste en crear por ley un centro o clínica que mediante información clara permita que los donantes o su familia puede recibir una contribución económica del favorecido o que el centro frente a incapacidad monetaria del enfermo pueda compensarle de alguna manera, por ejemplo, El pago de un seguro médico de por vida para el donante y su familia, posibilidad que la clínica pueda asumir un tratamiento médico o una cirugía para el donante o su familia, realizando esta actividad de la manera más respetuosa para a la digna del donante. Esta posición es cuestionable porque sería ello permitir la comercialización del ser humano y atentaría contra la dignidad de la persona al cosificarla para la venta.

En criterio de los autores de este artículo, si bien, el receptor no debe pagar por el órgano que necesita, como lo expresa la misma ley, sí debería pagar pague los costos que implica la sustracción de un órgano. En este sentido la ley 919 de 2004, así lo autoriza, cuando expresa que las instituciones que funcionen con la debida autorización como bancos de tejidos, médula ósea y las instituciones prestadoras de servicios de salud con programas de trasplantes habilitados, podrán cobrar los costos ocasionados por la hospitalización del donante vivo, el cuidado médico del mismo, el diagnóstico, la extracción, la preservación, las pruebas o exámenes requeridos previamente para la donación o el suministro, el transporte, el valor de las pruebas inmunológicas y de histocompatibilidad indispensables para la realización del trasplante, el valor del trasplante, gastos de hospitalización, cirugía y cuidado médico postoperatorio del paciente trasplantado y del donante, el suministro de medicamentos y los controles subsiguientes a dicho procedimiento, y en nuestra opinión debe reconocérsele al donante su disminución en su calidad de vida y el sufrimiento moral al someterse a una intervención en beneficio de otro. Creemos que quien ha recibido un órgano donado, aunque que sea por simple altruismo de otro, merece toda consideración y lo menos que puede hacer un receptor enfermo con nueva salud y vida, con recursos económicos, es ser generoso con su salvador y benefactor.

Para la doctrina dominante, y es la que sigue la ley 919, es la de prohibir la comercialización, entiéndase a título oneroso, de componentes anatómicos humanos para trasplante y tipifica algunos conductas como delito.

Con el surgimiento del tráfico de órganos, esto es, la comercialización, la compra venta de partes anatómicas del cuerpo humano a titulo retributivo, plantea para el derecho sancionador una respuesta a estas conductas irregulares. Para el profesor Francisco Farfán (2006, p. 95), la conducta que constituyen el comercio de órganos se pueden precisar en: venta de órganos humanos de una persona viva a otra para que la extracción de la parte anatómica suceda inmediatamente estando vivo o cuando el donante haya muerto; venta de un cadáver o de sus órganos por parte de sus sucesores; venta de órganos contra la voluntad del donante o sin el consentimiento de los deudos y la exportación de órganos en el tráfico internacional. Pero existen otras más, como sería la donación a título gratuito pero mediante engaño de la víctima lo que afecta su consentimiento en el acto de donación, el hurto de un cadáver o de sus partes.

Con la ley 919, por primera vez se crean en Colombia los tipos penales de determinadas conductas sobre el tráfico de órganos. Antes de esta ley todo se regula en forma genérica con los tipos referidos a lesiones personales en sus diferentes modalidades. Antes de la ley 919 en nuestro país, se podía comprar y vender órganos humanos a título oneroso. Como 
por ejemplo, la venta de órganos simétricos entre vivos, siempre que no existiera ningún vicio del consentimiento, la venta de cualquier órgano después de la muerte y la venta del cadáver o algunas de sus partes. Además, que existía la presunción de donación cuando los deudos no manifestaban lo contrario dentro de las seis horas siguientes a la ocurrencia de la muerte de una persona.

\section{CONDUCTAS PENALES QUE TRAE LA LEY 919 DE 2004}

\section{Delito de tráfico de órganos}

El art. 2 de la ley 919 de 2004, tipifica este delito en los siguientes términos: "Quien trafique, compre, venda o comercialice componentes anatómicos humanos". "Se prohíbe cualquier forma de compensación, pago en dinero o en especie por los componentes anatómicos." "Solo se permite la donación de componentes anatómicos; órganos, tejidos y fluidos corporales deberá hacerse siempre por razones humanitarias." (Farfán, 2006, p. 81).

Definen los autores de este artículo, el llamado "Tráfico de Órganos", como la compra y venta de los órganos de un individuo, vivo o muerto, con el fin de proveer de órganos humanos a personas que los necesitan para sobrevivir, y que generalmente cuentan con capacidad de pago, la cual se realiza en la mayoría de los casos a donantes generalmente de escasos recursos económicos.

La compraventa de órganos parte de la necesidad de obtención de un elemento orgánico humano para un enfermo con recursos económicos desesperado por una mejor calidad de vida a partir de una persona pobre sin recursos y necesitado por dinero para cumplir con deficiencias básicas para él o su familia.

Este tipo de donación de órgano a cambio de dinero o de cualquier otra retribución para el donante es lo que genera la ilicitud del acto de entrega del órgano vital. Ese deseo de seguir viviendo que se fundamente en un cambio de órgano es lo que acrecienta el negocio del tráfico o comercialización de partes del cuerpo humano. Un problema que no tiene límites para ellos se llega traficar con niños, con discapacitados a los cuales se les ofrece la oportunidad de venta, se les secuestra o hasta se les causa la muerte para obtener el órgano que se requiere ante la oferta tan creciente y cuantioso pago que puede ofrecer un enfermo rico ${ }^{3}$.

Otro factor, que fomenta el comercio de órganos es que su demanda es mucho más alta que la oferta legal. El principio de solidaridad en la donación de componentes anatómicos; órganos, tejidos y fluidos corporales que deberá ser humanitarias, se cambia por dinero o cualquier otra utilidad.

Las dificultades de obtener un órgano para un paciente en los países del primer mundo por la larga lista de espera es un factor que incrementa la comercialización ilegal de órganos humanos esto es lo que fomenta el llamado "turismo de trasplante" hacia los países más pobres del mundo, Colombia, Ecuador, Perú, India, etc. Estos países se buscan y eligen porque no existen medidas para prevenir estas actuaciones y sus legislaciones son muy laxas y en estos países constituye la criminalidad de menos interés para las preocupantes tasas de

3 Como ejemplo, sólo en México se realizan más de 4,000 trasplantes legales al año; aunque más de 8,000 personas están en lista de espera. De esa cantidad el 15\% muere al no recibir un órgano, informa el Centro Nacional de Trasplantes (Cenatra) de México. Se conocen casos en el mercado negro y de fuentes no formales que el hígado puede llegar a costar en promedio U $\$ 150,000$ dólares, así como por un riñón se puede llegar a pagar U $\$ 120,000$; por el corazón U\$60,000 y por la córnea U\$45,000. Ha sido también frecuente en Filipinas, Hong Kong y la China, países en los que los pobres venden un riñón por solo mil dólares a ricos procedentes principalmente del Japón. En menor grado también existe en muchos países del norte de África y sobre todo en Egipto, en los que con frecuencia en la prensa se leen anuncios de oferta de riñones por parte de personas desesperadas por la pobreza, beneficiando a ricos desesperados por seguir viviendo. En algunos países de América Latina, como Bolivia, en los que coexiste la extrema pobreza con la injusticia social y la falta de atención por parte del estado para cubrir las necesidades básicas de la población, incluyendo el tratamiento dialítico para sustituir la función renal perdida, los ricos también publican anuncios en la prensa solicitando riñones que son ofertados por personas agobiadas por la pobreza. Y de la misma manera, estas personas desesperadas por satisfacer alguna necesidad básica con dinero, publican anuncios en la prensa bajo el título de «Dono Riñón» tratándose en la realidad de la oferta de un riñón para la venta. 
delitos por hurto, homicidios, etc., que generan mayor reacción social para la comunidad (Lozada, 2008) ${ }^{4}$. Según el diario del oriente, en la dirección Web antes anotada "En Europa, en el año 2007, había 58.200 pacientes en lista de espera para poder recibir un riñón, un hígado o un corazón. En total se realizaron 25.900 operaciones; en Estados Unidos, la demanda de órganos sanos es más elevada, con 95.150 personas en las listas de espera; de las cuales 25.300 pudieron recibir un órgano sano. Estos datos son sólo una pequeña muestra del gran problema que supone en los países ricos poder obtener un órgano sano... Muchos de estos pacientes acabaron recurriendo al turismo del trasplante. (Lozada, 2008) ${ }^{5}$.

4 El precio de este singular 'paquete vacacional' puede variar desde los 47.000 euros- si el paciente quiere un riñón- o hasta los 108.000- si requiere un hígado. Estos servicios se pueden contratar, fácilmente, por internet. Fuentes informales.

5 En Brasil, la policía detuvo a once personas que conformaban una red que vendía órganos en Sudáfrica a un precio que oscilaba los 8.000 euros. Precisamente Brasil es uno de los principales escenarios donde se trafica con órganos humanos. El Gobierno maneja datos escalofriantes... El número de niños brasileños que salen del país en adopciones internacional no cuadra con el que se registra en el extranjero. Parece que hay niños que 'se pierden' por el camino. La pobreza que asfixia a millones de brasileños que viven hacinados en las favelas ha hecho que vendan a sus hijos por ingentes cantidades de dinero. Se puede comprar a un niño por unos 70.000 euros y luego vender sus órganos al mejor postor. En Mozambique, el fiscal general del Estado, desenmascaró una importante red de traficantes de órganos que se dedicaban a secuestrar y asesinar a niños para extraerles todos los órganos para su posterior venta en el mercado negro. Esta red, de la que se sospecha que pudo haber acabado con "bastantes vidas humanas", estaba dirigida por oficiales de policía locales. Los agentes solicitaban enterrar los cadáveres encontrados con la mayor brevedad posible para impedir que se hicieran autopsias oficiales y así descubrir la trama. En China, por ejemplo, son más sutiles. En las prisiones del gigante asiático se han denunciado importantes vínculos entre las mafias chinas y los funcionarios de prisiones, doctores y autoridades sanitarias que trabajan en las prisiones. Las mafias, tras abonar distintas cantidades de dinero, obtendrían los órganos de los presos que han sido ajusticiados o que simplemente han fallecido en la cárcel. En Colombia, uno de los países donde más riñones se venden de manera ilegal, cientos de personas acuden cada día a distintas clínicas para hacerse los pertinentes chequeos médicos para una posterior operación ilegal.
De conformidad con La ley 919 de 2004, que tipifica el comercio de órganos, la descripción penal establece unos verbos rectores alternativos: traficar, compre, vender, comercializar componente anatómicos del propio cuerpo, para ser extraídos en vida o después de la muerte del que vende, sancionando también, la compraventa de órganos que realizan los deudos del fallecido.

Es decir, la norma sanciona con pena a quien venda o compre un órgano, siempre que se haga como una contraprestación. Es decir, se reciba algo a cambio, dinero o cualquier otra utilidad. El delitos se perfecciona con el negocio, con el acuerdo de voluntades sobre el órgano a trasferir, no importa que no se logre la trasferencia o el vendedor no cumpla con lo pactado. En estas condiciones el delito seria de mera actividad no se quiere que se logre el resultado esperado.

El vendedor como el comprador serían los sujetos activos del delito. No siempre el que vende es el mismo donador, puede ser un tercero intermediario, puede ser el representante del banco de órganos, la clínica o del hospital a través de la cual se hace la negociación. El órgano pude ser de una persona viva o fallecida. En este caso serían los deudos los sujetos del delito. Siempre y cuando el negocio se haga a título oneroso. No se requiere para el tipo penal que exista una organización criminal para el tráfico. Con una sola vez que se realiza la compraventa se perfecciona el delito.

Si la donación se hace por razones humanitaria, debe existir también la voluntad del donador de querer hacerlo. Si se trata de un menor de edad, un discapacitado mental, una persona inconsciente, en coma o en estado de muerte cerebral; concretamente en un estado en el cual no puede manifestar su voluntad, es decir no hay consentimiento, lo mismo que si este se obtiene mediante fuerza, coacción, constreñimiento o engaño de la víctima. El delincuente seria el comprador. 


\section{Sustracción de órganos de un cadáver}

La ley 919 de 2004, tipifica este delito en los siguientes términos: En la misma pena incurrirá quien sustraiga, trafique, compre, venda o comercialice un componente anatómico de un cadáver. Quien done o suministre un órgano, tejido o fluido corporal deberá hacerlo a título gratuito, sin recibir ningún tipo de remuneración por el componente anatómico.

Con esta norma que solo menciona la sustracción de órganos debe entenderse que incluye el tráfico, la compra, la venta y comercialización de órganos o parte de un cadáver y lo que se prohíbe es la compensación, pago en dinero o en especie por los componentes anatómicos. Solo se permite la donación de componentes anatómicos; órganos, tejidos y fluidos corporales deberá hacerse siempre por razones humanitarias.

La norma gira entorno a la prohibición de compraventa de partes de una cadáver o sus restos a título oneroso, de manera que en nuestro criterio si la sustracción o la venta de las partes del cuerpo muerto se hace con fines científicos o académicos, prácticas médicas, estudios de enfermedades no sería delito, porque la finalidad no es trasplante o para ser revendidos.

El profesor Farfán (2006, p. 104), estima que es un delito contra la autonomía familiar, en donde lo que se protege es la dignidad de la persona, que aunque muerta inspira respeto, sin necesidad de acudir a ideas sobre el sentimiento religioso. Los sujetos activos de este delito, por la venta la partes del cadáver serían los deudos. Estarían acá los familiares directos: padres, hijos, abuelos, la cónyuge o compañera permanente que deciden negociar la venta de los órganos del cadáver. También se castiga a quien sustrae las partes sin requerir compraventa previa, conducta similar al que hurta esos órganos para negociarlos en tráfico órganos.

Es posible la sustracción de órganos de un cadáver si ser delito, cuando la persona en vida decide donar sus órganos y bajo la presunción legal de donación, que regula el art. 2 de la Ley 73 de 1988, cuando los familiares dentro de las seis horas siguientes a la ocurrencia de la muerte cerebral, o antes de iniciación de autopsia, no se oponen a la extracción de órganos del cuerpo sin vida de su pariente. Después de este lapso la familia pierde el derecho consagrado en la ley 73 de 1988 (Farfán, 2006, p. 105).

Con la presunción de donación, todos los colombianos no constituimos en donantes potenciales, una manera de legalizar la trasferencia de órganos. Difícilmente un deudo en la mayoría de los casos puede manifestar en esos momentos de dolor por la muerte de un familiar, la idea que no le sustraiga los órganos, aun enterándose de su fallecimiento y para manifestarlo dentro de las seis horas siguientes. Observe que no dice ante quien debe manifestarlo, si se pude hacer por teléfono, por correo electrónico, seguramente se exigirá que esa se haga por escrito. Solo pensar en los accidentes a diario y aun cuando se la haga seguimiento de la enfermedad terminal de un paciente puede fallecer en una hora, sin que haya alguien interesado en el hospital, clínica que informe a los familiares el deceso, para contar con el plazo para oponerse a la sustracción de piezas del cadáver. La donación por presunción, si se entendiera en su contexto jurídico ideal, sería un manera de combatir el tráfico de órganos de manera que personas sin recursos para obtener un órgano lo puedan hacer en forma igualitaria y equitativa de quien tiene medios económicos para presionar la búsqueda de un órgano. Mal entendió la presunción es la puerta abierta al tráfico y comercializan vulgar de órganos al mejor postor y esto es lo que la ley 919 quiere evitar.

\section{Sustracción de un órgano de una persona viva sin su consentimiento}

La ley 919 de 2004, tipifica este delito en los siguientes términos: En la misma pena incurrirá quien sustraiga un componente anatómico de una persona sin la correspondiente autorización.

Son situaciones donde el sujeto pasivo no está en condiciones de dar el consentimiento para 
autorizar la extracción de uno de sus órganos. Estados de inconsciencias por la anestesia, la droga, una situación de estar en coma. O situaciones serian donde la utiliza la coacción, el miedo, la amenaza, el engaño para lograr que donante ceda para que permita la sustracción de uno de sus órganos pares del individuo. En estos casos lo que sucede es que estamos frente a un concurso de delitos: secuestro, constreñimiento, amenazas, lesiones personales o el homicidio si como consecuencia la sustracción sobreviene la muerte de la víctima.

\section{El que sirve de intermediador en la compraventa del órgano para el trasplante}

La ley 919 de 2004, expresa, que incurrirá en la misma pena de tres a seis años de prisión para quien participe en calidad de intermediario en la compra, venta o comercialización del componente.

El intermediario en la compraventa de los órganos humanos, es la persona que contacta a otras: la que necesita el órgano y la persona donante que solicita el dinero. Es el que acerca al enfermo, al paciente con la persona que desea donar su órgano por dinero para realizar el intercambio oneroso de la transacción. El intermediación en la norma es una forma de coparticipación criminal. El intermediario es el que fomento le tráfico, participe un acto ajeno, luego no sería desde el punto de vista de lo dogmático penal el autor del delito. Estos son casos donde por norma expresa la complicidad o la determinación se convierte el coparticipe en autor y la norma penal lo castiga con la misma pena que para los autores del comercio del órganos, de tres a seis años de prisión. Si se observa la situación, el verdadero traficante es el intermediario que generalmente es el sujeto que con ánimo de lucro se queda muchas veces con la mayor parte de la negociación y aprovecha y abusa de la necesitad de los interesados en la comercialización del órgano.

Sobre estos nuevos delitos que buscan reprimir la compra venta de órganos humanos a titulo onerosos, estimada el profesor Farfán, que no resulta razonable que el derecho penal se ocupa de sancionar la compraventa de órganos simétricos, como lo riñones, pulmones, o parte de la piel, con fines de trasplante, pues con tal conducta no lesiona ni afecta la vida del donante que puede sobrevivir con el otro órgano. No se ve tampoco que daño le puede producir a alguien el que los deudos decidan vender parte de los órganos o el cadáver de un familiar pues "tal determinación tutela única y exclusivamente la concepción religiosa que postula y defiende la sacralidad del cuerpo sin vida desconociendo así que en un Estado pluralista, y en el marco de una constitución que establece como uno de sus principios esenciales la diversidad étnica y cultural, no es posible imponer a través del derecho penal una concepción religiosa oficial en torno a la naturaleza del cadáver, pues una decisión de esta naturaleza es a todas luces arbitraria y no guarda armonía con los postulados que integran la Carta Política" (Farfán, 2006). Por lo anterior, estima que debe penalizarse la intermediación de órganos obtenidos contra la voluntad de los donantes o la voluntad de los familiares del difunto.

\section{Publicación para la compraventa de órganos}

Expresa la ley 919 de 2004 en el Parágrafo único del artículo segundo en la misma pena de tres a seis años incurrirá quien realice publicidad sobre la necesidad de un órgano o tejido sobre su disponibilidad, ofreciendo o buscando algún tipo de gratificación o remuneración.

Con la norma se pretende prohibir el ofrecimiento público por los medios de comunicación: periódico, radio, televisión o distribución de facsímiles o la utilización de la redes de internet sobre la información de contactos de quienes necesitan un órgano para trasplante o de quienes lo ofrecen a cambio de dinero. Es una manera de limitar el tráfico de órganos ilegales. Las pregunta esta si es el propio donante el que se anuncia comete el delito? Creemos que no, el suicidio y las autolesiones voluntarias y las promesas de 
hacerlo a cambio de dinero hace parte de la libre autodeterminación y desarrollo de la personalidad de las personas. En estos caso se castigaría al comprador del órgano a su intermediario, al representante del medio de comunicación o la persona que autorizo el anuncio.

\section{CONCLUSIONES}

Con las disposiciones de la ley 919 de 2004 que tipifica algunas conductas para reprimir el tráfico de órganos, resulta una manera de política criminal de Estado para sancionar a aquellas personas que a titulo onerosos compra o venden órganos humanos de personas viva o que han fallecido. Lo mismo cuando el órgano es sustraído contra la voluntad del donante o se obtiene mediante violencia, engaño, coacción de la víctima.

Difícil tarea de acabar con el tráfico y comercialización de órganos humanos, pues un acto oneroso de compraventa que será de manera verbal, se puede simular con la entrega de la retribución de cualquier otra forma. De otra parte, impide una donación voluntaria y por razones humanitarias, en donde el receptor agradecido quiera beneficiar a su donante, sea mediante bienes para él o su familia? La donación de bienes y dinero al donante no está prohibida, porque el mero desprendimiento de dinero y otra utilidades a su benefactor no está sancionada. Además, obsérvese que la ley permite que al donante y el banco o la clínica de órganos pueden recibir dinero a cambio del órgano si se realiza con el fin de sufragar los diferentes gastos y costos para mantener el órgano, para la cirugía y salud posterior del donante y entre estos gastos esta acaso prohibido que al donante por el daño moral o la disminución de su calidad de vida no pueda recibir algún bien a cambio, sin que se entiende que este pago se entienda como retribución? Así lo expresa textualmente la norma, en el párrafo único del artículo $2^{\circ}$ de la Ley 919: "Las instituciones que funcionen con la debida autorización como bancos de tejido y de médula ósea y las instituciones prestadoras de servicios de salud con programas de trasplantes habilitados, podrán cobrar los costos ocasionados por la hospitalización del donante vivo, el cuidado médico del mismo, el diagnóstico, la extracción, la preservación, las pruebas o exámenes requeridos previamente para la donación o el suministro, el transporte, el valor de las pruebas inmunológicas y de histocompatibilidad indispensables para la realización del trasplante, el valor del trasplante, gastos de hospitalización, cirugía y cuidado médico postoperatorio del paciente trasplantado y del donante, el suministro de medicamentos y los controles subsiguientes a dicho procedimiento."

Como política criminal para combatir este tipo de delincuencia que surge con el tráfico de órganos en forma irregular, es aplicable la educación, la formación cultural a la comunidad y que mediante una ley todos los colombianos seamos donantes de órganos una vez fallecidos y permitir la trasferencia de órganos en forma remunerada siempre que se haga en un establecimiento clínico, hospital o banco de órganos debidamente autorizado, siempre y cuando no se comprometa con la donación entre vivos la salud del donante y se haga en forma voluntaria con información al paciente y su familia de la consecuencias del acto, es decir, con consentimiento informado.

\section{BIBLIOGRAFÍA}

ÁVILA, A. (2005) Colombia, un país líder en trasplantes. En: Arqueología, medicina, curanderismo: a propósito de la «Colección Orticochea». Bogotá. Amarey Nova-Medical S.A. Buenos Aires. Recuperado el 27 de abril de 2011 de: http://www.bioetica.uchile.cl/doc/trasplan.htm

CARMONA, J., ESCOBAR, J., GALVIS, C., NÚÑEZ, L.E., SÁNCHEZ, C., OVALLE, C., PEÑARETE, D. (1999). Temas de Bioética en Colombia. Tomo 8. Facultad de Educación. Programa de Bioética. Universidad El Bosque. 
CARRAL NOVO, J., PARELLADA, J. (2003). Problemas bioéticos para la donación postmorten para trasplantes de órganos. En: Revista Cubana de Medicina Intensiva y Emergencias. Volumen 2. Disponible en: http://bvs.sld.cu/revistas/mie/ vol2_2_03/mie10104.htm\#cargo

CASADO, M. (2004) Las Leyes de la Bioética: Una tarea común. Barcelona: Editorial GEDISA.

CASADO, M. (2007) Nuevos Materiales en Bioética y Derecho. México. Distribuciones Fontamara S.A.

CÓRDOBA, R. (2005) La Bioética y la práctica médica posmoderna. Instituto de Ética y Bioética. Medellín: Universidad Pontificia Bolivariana.

CUSUMANO, A., GARCÍA, G., GONZÁLEZ C. (2006). The latin american dialysis and transplant registry: report 2006. Recuperado el 27 de Abril de 2011 de: http://www.ishib.org/journal/19-1s1/ ethn-19-01s1-3.pdf

ESCOBAR, J., DA COSTA, M., JÁCOME, S., HALAGA, H., MALDONADO, C., MONTT, J., RODRÍGUEZ DEL POSO, P., GARCÍA, G., RODRÍGUEZ, C. (1999). Bioética y Justicia Sanitaria. Bogotá: Ediciones El Bosque.

ESCOBAR, J., MALDONADO, C., RODRÍGUEZ, DELPOSOP., HOTTOIS, G., SANTOSYVARGAS, L., GAVIRIA, C., PARENTI, F., GARCÍA, G. (1998) Bioética y Derechos Humanos. Bogotá: Ediciones el Bosque.

ESCRIBAR, A., PÉREZ, MANUEL., VILLARROEL, R. (2008). Bioética. Fundamentos y Dimensión Práctica. Santiago: Editorial Mediterráneo Ltda.

FARFÁN, F. (2006). Tráfico de Órganos Humanos y Ley penal. Instituto de Estudios del Ministerio Publico. Procuraduría General de la Nación.

FUENZALIDA-PUELMA, HL. (1990). Trasplante de órganos: la respuesta legislativa de América Latina. En: Bioética: Temas y Perspectivas. OPS 1990; 108(5-6): 69-86.

GARZÓN, F (2000) Bioética: Manual Interactivo. Primera Edición. Bogotá. 3R Editores Ltda.
GARZÓN, F (2009) Aspectos Bioéticos del Consentimiento Informado en Investigación Biomédica con Población Vulnerable. En: Revista Latinoamericana de Bioética. Vol.9 Edición. 17 Número.2. Universidad Militar Nueva Granada. Bogotá.

GÓMEZ,A.I;MALDONADO, C. COMPILADORES (2005) Bioética y Educación. Investigación, problemas y propuestas. Bogotá: Centro Editorial Universidad del Rosario.

GUILLON, RAMNAN. «TRANSPLANTATION AND ETHICS» EN: THOMASMA, D; KUSHNER, $T$ (1996) Birth to Death Science and Bioethics. Cambridge University Press.

GUERRA, YOLANDA; TIRADO MISAEL, MÁRQUEZ ÁLVARO. Trasplante de órganos, Bioética y legislación comparada. Universidad Militar Nueva Granada. 2011.

LÁZARO, S (s.f.) Tráfico de Órganos. En:http:// www.monografias.com/trabajos35/comercio-deorganos/comercio-de-organos.shtml.

LÓPEZ, A (2006) Temas candentes de bioética y familia: en la brecha. Madrid. Ediciones Palabra S.A.

LOZADA, A (2008) El lucrativo mundo del tráfico de órganos. Disponible en: http://diariodeoriente. mforos.com/1626400/9062891-el-lucrativo-mundo-del-trafico-de-organos-los-judios-manejanel-comercio/.

MANCINI, R (2002) Conflictos bioéticos en trasplante de órganos y tejidos. 1er. Encuentro Ibero-Americano sobre «Trasplante de Órganos y Tejidos»

MÉNDEZ, VÍCTOR; SILVEIRA, H. C (2007) Bioética y Derecho. Barcelona: Editorial UOC.

MENDOZA, J Algunas preocupaciones de la Bioética en Relación con la Medicina para el siglo XXI. En: Gómez, A. I (2005) Bioética y educación: investigación, problemas y propuestas. Bogotá. Universidad del Rosario.

PARDO, ANTONIO (2010) Cuestiones Básicas de Bioética. Instituto de Ciencias para la Familia. Universidad de Navarra. Ediciones Rialp S.A. 
PARRILLA, P; RAMÍREZ, P; RÍOS, A (2008) Manual sobre Donación y Trasplante de órganos. Madrid. Arán Ediciones S.L.

REINA, L (2006, 27 de Octubre) Optimismo por el crecimiento de la donación de órganos en América latina. La Nación. Recuperado el 25 de Abril de 2011, de: http://www.lanacion. com.ar/nota.asp?nota_id $=853085$

SANTIAGO-DELPÍN EA, GARCÍA VD Organ transplantation in Latin America.
SECRETARÍA DE SALUD DE BOGOTÁ (2007)

La Donación y el Trasplante de Órganos y Tejidos. Direccion de Desarrollo de Servicios de Salud.

SOCIEDAD DE TRASPLANTES DE AMÉRICA LATINA Y EL CARIBE. DURO, VALTER (2009) Latin América Trasplantation Report. http://www.grupopuntacana.org/materiales/ RBT_LATINO_2009-final.pdf

Transplant Program, Hospital and Department of Surgery, University of Puerto Rico Medical School, San Juan, Puerto Rico. 